This item was submitted to Loughborough's Research Repository by the author.

Items in Figshare are protected by copyright, with all rights reserved, unless otherwise indicated.

\title{
When good news is bad news: the negative impact of positive customer feedback on front-line employee well-being
}

PLEASE CITE THE PUBLISHED VERSION

http://dx.doi.org/10.1108/JSM-01-2015-0052

PUBLISHER

(C) Emerald

VERSION

AM (Accepted Manuscript)

\section{PUBLISHER STATEMENT}

This work is made available according to the conditions of the Creative Commons Attribution-NonCommercialNoDerivatives 4.0 International (CC BY-NC-ND 4.0) licence. Full details of this licence are available at: https://creativecommons.org/licenses/by-nc-nd/4.0/

\section{LICENCE}

CC BY-NC-ND 4.0

\section{REPOSITORY RECORD}

Nasr, Linda, Jamie Burton, and Thorsten Gruber. 2019. "When Good News Is Bad News: The Negative Impact of Positive Customer Feedback on Front-line Employee Well-being”. figshare.

https://hdl.handle.net/2134/20906. 


\section{When good news is bad news: The negative impact of positive customer feedback on front-line employee well-being}

\section{Introduction}

"Praise, like penicillin, must not be administered haphazardly. There are rules and cautions that govern the handling of potent medicines-rules about timing and dosage, cautions about possible allergic reactions" (Ginott, 1965).

A large number of studies have been conducted in the field of service encounters over the last 40-50 years of service(s) marketing history (Baron et al., 2014). However, service literature has a strong focus on "dark side" topics, focusing for example on the impact of customer complaints, dysfunctional customer behavior, and customer rage on Front-Line Employees (FLEs), other customers and companies in general (e.g. Surachartkumtonkun et al., 2015). Recently, researchers have pointed that the "bright side" of service encounters has been surprisingly neglected; either by encouraging research and practices that underserves groups in need or by proposing and advancing a patronizing style of service delivery (Fisk, 2009). Responding to this criticism, Anderson et al. (2013) highlighted the importance of studying what affects the "well-being" of entities involved in a service encounter. This focus on "well-being" triggered the establishment of the Transformative Service Research (TSR) movement. Arising at the convergence of Transformative Consumer Research (TCR) and service research (Anderson et al., 2013), TSR is defined as "service research that centers on creating uplifting changes and improvements in the well-being of individuals (consumers and employees), families, social networks, communities, cities, nations, collectives, and ecosystems” (Ostrom et al., 2010, p. 6).

One of the main current research priorities within TSR is to focus on service entities' well-being, in particular the well-being of FLEs (Anderson et al., 2013). Although FLEs play a crucial role in the service delivery process, their well-being remains marginalized within service research. Thus, TSR calls for studies that uncover and analyze the aspects of the service encounter that have the potential to affect the well-being of FLEs. Nasr et al. (2014), drawing on positive psychology and positive organizational behavior theory, identified Positive Customer Feedback (PCF), exchanged during a service encounter, as having a transformational potential and a positive impact on the well-being of FLEs. However, Wood et al. (2010) reviewing positive feedback and well-being, noted that: "no research has examined whether there might be a negative side associated with gratitude” (p. 13). These contrasting bodies of literature led us to the provocative question: Could the apparently positive construct "Positive Customer Feedback" have a negative impact on the well- 
being of front-line employees? Answering this question will reveal potential negative impacts of PCF, and will contribute to research on TSR and PCF.

We begin the paper by introducing the theoretical foundations and aspirations of TSR. We then focus on the under-researched area of FLE well-being, followed by a discussion about the transformational potential of PCF. Subsequently, we conduct a multidisciplinary review of extant literature related to positive feedback particularly in the social psychology and organizational behavior fields to support our assumptions about the potential negative impacts of PCF. We then describe the research design and methodologies employed, and follow this with the key findings; proposing a model portraying the identified negative impacts and contingencies of PCF (i.e. under what circumstances PCF has a greater/lesser negative impact). We conclude the article with a discussion of the implications for service managers, the study limitations, and the proposed directions for future research.

\section{Literature review}

\section{Transformative Service Research (TSR)}

According to a recent study conducted by Ostrom et al. (2015, p. 140), "Improving well-being through transformative service” is ranked as the most important service research priority. The main aim, within this priority, is to investigate the well-being implications of service. Anderson et al. (2013) developed a framework illustrating how interaction between service entities (employees, processes, offerings, organizations, and service sectors) and consumer entities (individuals, collectives, and the ecosystem) influences the well-being of both. The TSR framework focuses on two key types of well-being: eudaimonic and hedonic (Anderson et al., 2013), together referred to as psychological well-being (Robertson and Cooper, 2011). Eudaimonic well-being is linked to the idea of realizing a potential (Ryff, 1989) and having a purpose (Robertson and Cooper, 2011). Hedonic well-being is linked to the feeling of happiness (Diener et al., 1999) and consists of life satisfaction, positive affect, and the absence of negative affect.

With the establishment of these theoretical foundations and the development of the TSR research agenda for the future (Anderson et al., 2013), TSR is being acknowledged as a very promising and rich research field (Bitner, 2014). It is gaining significant attention from researchers in the service area and beyond and has successfully established itself as an important subfield within service science (Baron et al., 2014).

Despite this rapid success, more work is needed in the field of TSR, as many questions remain unanswered and further studies are needed to enlarge the current boundaries of service research and enhance it with a transformative outlook. One of the areas that requires further attention is the well-being of service 
entities - in particular the well-being of FLEs. Recently, TSR researchers realized the need to further investigate service provider well-being, as most of the research conducted within TSR focuses solely on the well-being of consumer entities. Moreover, TSR holds that: "Service entities are aspects of services that consumer entities interact with that can positively or negatively affect their well-being” (Anderson et al., 2013, p. 1205). Since most services are experiential in nature, co-creating service offerings and interacting with service employees is essential for service delivery, thus, such experiences are likely to significantly affect the well-being of the parties involved (Anderson et al., 2013). Therefore, the well-being of FLEs can have an indirect impact on the well-being of customers; consequently there is a need to understand how the various aspects of the service encounter affect the well-being of FLEs.

\section{Importance of front-line employees}

"Understanding organization and employee issues relevant to successful service” is identified as one of the 12 service research priorities (Ostrom et al., 2015, p. 127). Thus, despite the evolution of technology, it still cannot substitute the human being (Brynjolfsson and McAfee, 2011) and FLEs continue playing a crucial role in service encounters.

FLEs are customer-contact employees such as customer service representatives, retail employees, and delivery personnel who perform their work duties under the limitations of both the internal and external organizational environments (Edmondson and Boyer, 2013). Due to the interactivity of most services, customer's perception of service quality is often linked to the attitudes and behaviors of FLEs (Teng and Barrows, 2009). FLEs are the "face” of the service firm (Rupp et al., 2007) and in many cases "the first and only representation of the service firm” (Hartline et al., 2000, p. 35). Moreover, a number of studies show that employee outcomes are correlated with customer outcomes in the service sector (Yoon and Suh, 2003). Therefore, it is not surprising that most of the customer feedback received by service companies has FLEs as the main subjects and recipients (Lovelock and Wirtz, 2010; Nasr et al., 2014).

For organizations, FLEs are the main source of information about their customers and the process of resource integration in the service encounter (Bettencourt et al., 2001). Consequently, van der Heijden et al. (2013) confirm that FLEs can capture customer responses, improve organizational processes, and facilitate service recovery.

In sum, FLEs play a crucial role in determining positive customer outcomes. As industries move to develop ever greater service focuses, and with the growing competition in the service economy coupled with the recent global crises, customer outcomes and the delivery of better service quality become an even more significant measure of the success of an organization (Farrell and Oczkowski, 2012). Thus, service 
organizations that understand the importance of FLEs, should direct their efforts beyond the management of employees’ performance to include the management of employees’ well-being.

The strategic priority identified by Ostrom et al. (2015), calls for research that helps understanding how consumer behavior affects FLEs satisfaction, job performance and overall well-being. In particular, it advances the question of "How do the employees' service experience (their well-being and value acquired) and the customers’ service experience affect each other?” (p. 135). Thus, stressing the importance of studying the factors affecting FLEs’ well-being as these would have an impact on the customers’ service experience.

\section{Front-line employee well-being}

As the existing service research literature on FLE well-being is scarce (Anderson et al., 2013), we refer to human resources and organizational behavior studies to further understand FLE well-being. Management and human resources literature have extensively focused on organizational well-being, with a number of studies providing insights into different employee-related mechanisms affecting service delivery (Ryan and Ployhart, 2003).

Historically, mental health of employees has been recognized as essential for organizational survival (Weehuizen, 2008) and it coincides with the emergence of positive psychology that shifted the focus from malfunctioning to human strength and flourishing. Consequently, through the emergence of positive organizational behavior theory, researchers started considering more positive approaches to organizational behavior (Money et al., 2009).

Positive organizational behavior theory is defined as "the study and application of positively oriented human resource strengths and psychological capacities that can be measured, developed, and effectively managed for performance improvement in today’s workplace” (Luthans, 2002, p. 59). Positive organizational behavior focuses on studying efficacy, hope, optimism and resilience - later referred to as Psychological Capital (PsyCap) of employees (Luthans and Youssef, 2004). (Avey et al., 2010) found that PsyCap capabilities have a positive impact on employees’ psychological well-being. Simultaneously, a large number of studies in the human resources and organizational behavior fields investigated the role of work characteristics in influencing the employee well-being (Bakker and Demerouti, 2007). For example, it has been found that work pressure, role ambiguity and emotional demands can cause exhaustion, sleeping problems and weakened health (e.g. Doi, 2005)

From a managerial perspective, it is important to manage employee psychological well-being as it is linked to employee morale and motivation, productivity and job satisfaction, and employee engagement and commitment (Robertson and Cooper, 2011). Therefore, according to Harter et al. (2002), employee 
psychological well-being has important consequences for the quality of the service encounter, customer satisfaction, and loyalty levels; which in turn have direct impact on organizations and communities. Thus, highlighting the need to understand and manage the aspects of the service encounter that can have an impact on the psychological well-being of FLEs.

Chan et al. (2010) called for further research to examine the elements of the co-creation process that influence employee stress levels and feelings of happiness. At the same time TSR researchers called for studies that focus on identifying new transformative potential within the direct and dialogic interaction between service and consumer entities (Rosenbaum et al., 2011). Subsequently, in one of the few TSR studies conducted in the area of service entities' well-being, Nasr et al. (2014) identified customer feedback as having a transformative potential able to affect the well-being of FLEs. They propose that since customer feedback is exchanged with FLE during a value-creation process, it is, according to the premise of Anderson et al. (2013), likely to significantly affect the well-being of both.

\section{Customer feedback}

Customer feedback in the service literature is conceptualized as customer communication concerning a product or a service (Erickson and Ecktich, 2001). There has been a substantial amount of work done in the area of customer feedback management and numerous outcomes of customer feedback have been identified, such as: assistance in performance assessment, facilitation of organizational learning (Babbar and Koufteros, 2008), enhancement of overall service quality (Wirtz et al., 2010), improved decision making (Bitner et al., 1994) and generation of competitive advantage (Lusch et al., 2007).

Customer feedback literature within the service area mainly focuses on solicited (firm requesting the information) customer feedback as opposed to unsolicited (collated without the firm requesting the information) feedback. Moreover, the literature tends to cluster around a limited number of negative themes: customer complaining behavior, customer dysfunctional behavior, customer rage and service recovery also referred to as dissatisfaction management (Daunt and Harris, 2014). This literature is mostly aimed at solving problems and providing guidelines as to how negative feedback can be learned from and avoided in the future. Conversely, few studies in the service field looked at the positive valence of customer feedback (Erickson and Ecktich, 2001; Kraft and Martin, 2001; Nasr et al., 2014; Payne et al., 2002; Villarroel Ordenes et al., 2014) leaving the field surprisingly marginalized, thus creating a research gap.

A focus on the impact of conflict and other negative elements of service encounters on FLEs satisfaction and customer orientation remains relevant (Briggs et al., 2015). However, in this study, inspired by the TSR objective to "create uplifting changes and improvements in the well-being” (Ostrom et al., 2010, p. 6), and 
positive psychology research that calls to focus on the positive manifestation of human behaviors by studying human virtue rather than human vice (Myers and Diener, 1995), PCF is adopted as a service aspect that is likely to affect the well-being of service entities, in particular FLEs. We focus on unsolicited PCF and accordingly we follow the definition presented by Kraft and Martin (2001) describing positive feedback as a (verbal or written) compliment taking the form of an acknowledgment or an expression of gratitude having the FLE as subject.

As might be expected, it has been found that when feedback is positive, the impact on FLE well-being is also positive; leading to the creation of positive relationships and a more productive and happier FLE (Nasr et al., 2014) and satisfying the employee's need for social approval, affiliation, and esteem (Eisenberger et al., 1990). Adopting a similar line of thinking to Wood et al. (2010) who questioned whether gratitude could have a negative side, we examine whether PCF can have negative impacts.

While the possible negative impact of PCF has not been investigated in the service literature per se, there are two neighboring research areas that provide a strong theoretical background and basis for the current argument: social psychology and organizational behavior research.

\section{Positive feedback in social psychology research}

Positive feedback in social psychology research is referred to as praise. Praise has been defined as: "Positive evaluations made by a person of another's products, performances, or attributes, where the evaluator presumes the validity of the standards on which the evaluation is based” (Kanouse et al., 1981, p. 98).

Praise is a social event that is frequently examined from the "perspective of reinforcement” (Meyer, 1992, p. 259). Thus, praise is designed to strengthen the probability of a particular action or behavior. The majority of early research conducted around praise, stresses its positive reinforcement impact and considers praise a popular tool to develop and maintain individuals' academic achievement motivation, behaviors, and strategies (Koestner et al., 1989). It is also assumed, that praise affects behavior when it is: performance related, specific and appears to be sincere (O’Leary and O’Leary, 1972).

Classified as a social approval technique, praise impact has been evident in the behavior modification literature where it is used; as a tool to reduce problems, encourage learning, and influence a variety of behaviors (Madsen et al., 1977). Social psychologists also found that praise has been positively correlated with self-

perceptions of ability (Blumenfeld et al., 1982) and is believed to boost self-efficacy (Bandura, 1997), which subsequently enhances feelings of pride and expectations for success in the future (Weiner, 1992). In addition, Deci and Ryan (1985) propose that praise boosts feelings of competence and autonomy and reinforces the association between response and positive outcomes since positive feedback encourages spending more time on a task. Praise has been found to improve adults’ performance at skilled tasks (Baumeister et al., 1990), offer 
motivating information about normative excellence (Koestner et al., 1990) and help in making friends and influencing people (Carnegie, 1964). Delin and Baumeister (1994) have explained these positive outcomes of praise as being due to positive mood enhancement and making the receiver “feel good about themselves".

The negative impact of praise:

Conversely, recent research questions common assumptions about praise and stresses the idea that outcomes of praise are not always constructive. According to Corpus and Lepper (2002) just because anything is termed a "positive reinforcer" does not mean that it always leads to enhancing effects.

Few researchers completely discourage praise, or claim that it is totally unnecessary (Kohn, 1993) while cultural psychologists claim that praise is not universally necessary or commonplace, since it does not exist in all cultures (Maynard, 2002). However, Meyer (1992) found that praise and other behaviors such as pity, help, assignment of easy tasks, which are mostly regarded as positive and desirable, can actually have negative impacts as they can unintentionally convey messages of perceived low-ability. In addition, praise has been found to create excessive pressure to continue performing well in the future (Baumeister et al., 1990), discourage risk taking (Gunderson et al., 2013), and reduce perceived autonomy (Birch et al., 1984).

Moreover, praise can create pressure and excessive self-consciousness (Baumeister et al., 1990) and painful negative self-attributions after failure (Tangney and Dearing, 2002). This can encourage invidious social comparison (Corpus et al., 2006) where instead of being a bridge connecting people, it may actually lead to negative comparisons and create distance between them. Finally, praise can contribute to shifting the locus of causality from internal to external sources (Deci and Ryan, 1985), leading to failure to generate proper responses to setbacks, ultimately resulting in decreased performance (Mueller and Dweck, 1998).

Praise can be interpreted in a variety of ways, and it is the interpretation of this feedback that dictates the recipient's response to it (Hattie and Timperley, 2007). Corpus and Lepper (2002) confirmed Meyer’s (1992) findings, claiming that praise should not be regarded as a one-way interaction - from the evaluator to the recipient - but rather as a complex social communication in which the role of the recipient is just as crucial as the role of the evaluator.

In sum, there is sufficient evidence in social psychology literature supporting arguments at both ends of the praise spectrum. In some contexts, praise is beneficial, and in others, it is detrimental. Therefore, the predominant view in service literature that positive feedback has only overwhelmingly positive outcomes (Nasr et al., 2014) is misguiding and should be investigated further in a service context.

\section{Positive feedback in organizational behavior research}


Historically in the organizational behavior field, performance feedback has been regarded as a tool to improve employee performance. Research demonstrates that the delivery of specific and timely performance feedback improves learning, boosts individual motivation, development, career planning, and performance management (London and Smither, 2002).

Waldersee and Luthans (1994) proposed that employees have performance standards of their own against which they measure their work performance. Thus, it is believed that if an employee receives negative feedback, which indicates a negative deviation from his/her set performance standards, this person will be motivated to work harder in order to meet the standards set, thus his/her performance improves.

However, there have been contradictory management studies questioning the effectiveness of feedback in improving performance, in particular regarding positive feedback. For example, recently Van Dijk and Kluger (2011) found that positive feedback increases motivation for a task that people “want to do” and decreases motivation for a task that people "have to do". Bandura and Cervone (1986) further explained that in routine tasks, role clarity and self-efficacy are already high, therefore, positive feedback is not needed and is eventually disrupting. Moreover, a recent study shows that praising employees by labeling them as having high potential, makes them more risk-averse (Kotlyar et al., 2014).

In sum, and based on the above claims that positive (performance) feedback has both negative and positive impacts on employees in organizations, there is a need to take into account the individual and situational factors that might be interacting and affecting the impact of feedback. Moreover, there is a need to further investigate unsolicited PCF in a service encounter due to the unique and experiential nature of encounters involving direct and immediate interaction with customers as opposed to performance feedback that is mainly delivered by managers.

\section{Research question}

Taking the overarching topic of service entities' well-being as main driver for this study, and positioning PCF as a service aspect that has an impact on the well-being of FLEs, we argue, based on the multidisciplinary literature reviewed, that the impact of PCF could be counterintuitive at times, as it might have a negative impact on the well-being of service entities, in particular FLEs. Therefore, the counterintuitive research question that this study aims to answer is:

Research Question: Could the apparently positive construct “Positive Customer Feedback” have a negative impact on the well-being of front-line employees?

Consequently, working within the TSR framework, we propose that PCF can negatively affect the eudaimonic and hedonic well-being dimensions of FLEs, thus decreasing their overall psychological well-being 
level. Moreover, we are interested in identifying possible contingencies that can determine the direction and intensity of the negative impact of PCF.

Although a large number of studies in the human resources, organizational behavior and marketing fields investigated the negative impacts of services on FLE (such as the negative impact of emotional labor in service roles (Ashforth and Humphrey, 1993); the negative impact of empowerment on FLEs (Hartline and Ferrell, 1996) and the negative impact of dysfunctional customer behavior (Harris and Reynolds, 2003), we

have not found any prior studies exploring the negative impacts of PCF on FLEs well-being in a service setting. Therefore, due to the limited current service literature on FLE well-being and the poorly understood concept of unsolicited PCF, a design focused on exploration and theory generation was considered most appropriate to gain a deeper understanding of this under-researched, but important topic. Thus, we conducted an exploratory qualitative study consisting of two components: focus groups with FLEs and interviews with managers working in the service sector.

\section{Research design and methodology}

\section{Data collection methods}

Focus groups with front-line employees:

In order to explore FLEs' perception and hands-on experience with the negative impact of PCF, focus groups with FLEs were conducted following the guidelines of Stewart et al. (2007): Prior to conducting the focus groups, an interview guide was developed based on the literature reviewed and subsequently this was piloted with a convenience group of FLEs, who were not part of the main sample, to make sure that the questions were clear, met the set objectives and stimulated a discussion among the participants. Once, the interview guide had been validated, the lead researcher conducted the focus groups. All focus groups began in an exploratory manner, focusing on each company’s practices and customer feedback policies. The overarching goal of the focus group was to discuss thoughts, feelings, experiences, and behaviors associated with receiving unsolicited PCF and its potential negative impacts. The moderator took care to secure that in every focus group the topics of interest were covered and that all participants had the chance to express themselves in their own words. Moreover, the moderator used the probing technique to go beyond the set topics in an unobtrusive and nondirective manner (McCracken, 1988). Respondents were also encouraged to provide examples of memorable service encounters entailing PCF occurrences. This approach allowed us to better understand FLEs' attitudes, 
beliefs, individual and situational factors, emotional responses, and behaviors towards receiving unsolicited PCF.

Managerial interviews:

Morgan and Spanish (1984) highly encourage the conjunction of focus groups with individual interviews. Moreover, they advocate that the systematic differences appearing between the data gathered in focus groups and in individual interviews are beneficial for theory generation. Following their generic recommendations and due to the nature of the study where managers are directly involved in the management of PCF, routinely witnessing employees receiving and being affected by it, managerial interviews were conducted to gain insights into managers opinions as to how unsolicited PCF affects the well-being of FLEs.

The objective for conducting the focus groups was to gain a multitude of insights into the various negative impacts of PCF as experienced by the recipients of this feedback. By contrast, the objective of the managerial interviews was to go deeper into the analysis of managerial and companywide opinions regarding the possible contingencies and negative impacts of PCF on FLEs. The assumption was that managers, due to their neutral supervisory position, might be able to spot further types of negative impacts and contingencies that the FLEs might not be aware of or might feel reluctant to discuss.

A semi-structured interview guide was developed based on the literature reviewed and on the initial insights emerging from the focus groups. However, due to the nature of the semi-structured interviews conducted, most of the managers shared ideas not covered by the interview guide. Consequently, the structure and schedule of the interviews were flexible in that they advanced as the interviews progressed focusing on key themes raised by both the schedule and the interviewees.

\section{Sampling and data collection and analysis}

Our sampling strategy did not aim for "generalizability” and "representativeness” rather to find an "appropriate sample” consisting of participants who can best answer the research question (Bowen, 2008) and offer and “efficient and effective saturation of categories, with optimal quality data and minimum dross” (Morse et al., 2002, p. 18). Accordingly, we identified “information-rich cases for study in depth”, as recommended by Patton (1990, p. 169) and started our data collection from a large pool of cases. These information-rich cases were amongst the most successful and largest service companies in the UK with a large customer base, representing various service industries. The customer management departments were contacted and they subsequently provided access to the participants they believed could provide the best answers to the research question. This 
strategy came in accordance with Patton (1990) who recommended the "cooperation of key informants, such as program staff or knowledgeable participants” (p. 174) who can help identify the most relevant participants.

We concluded our data collection at the stage where "theoretical saturation” was reached (Strauss and Corbin, 1998); a point in data collection where additional focus groups and managerial interviews stopped generating new insights. Accordingly, the sampling, the data collection and the data analysis were conducted simultaneously. Consequently, we kept bringing new participants continually into the study until no new insights were obtained, no new themes were identified and no further issues were arising regarding a particular category of data (Strauss and Corbin, 1998). It was only then that we concluded that the data categories were well established and validated and thus we reached a point at which to end the research (Morse, 1995).

The transcripts of the focus groups and managerial interviews were analyzed via an iterative hermeneutical process outlined by Turner (1981) and adopted from Wirtz et al. (2010). The process consisted of two stages: At first, a close reading of all the individual transcripts was conducted and the most compelling negative impacts were recorded and coded. Adopting the constant comparative method and Strauss and Corbin's (1998) coding procedures, three types of coding were used to analyze the transcripts. First, open coding was performed to identify the first-order codes (core categories) particular to every individual transcript. During this stage, we reduced the large textual data into manageable groupings where we used the key phrases in the transcripts as open codes in the analysis. The respondents' exact words, also known as “in vivo” codes (Bowen, 2008, p. 143) were used as preliminary concepts to organize the larger chunks of data. Second, axial coding (Locke, 2001) was used to consolidate and link the theoretical categories generated from all the transcripts which were more abstract in nature than the core categories. During this stage, the most common and frequently occurring key terms were initially used as conceptual categories, however as the analysis continued, the exact words from the transcripts (descriptive mode) were exchanged by more interpretative codes (explanatory mode) (Bowen, 2008). Third, selective coding was used to identify the aggregate theoretical dimensions (global themes) by grouping all the theoretical categories and selecting the dimensions that integrate and refine the theory. These codes were created by consolidating and connecting the axial codes while abstracting even further from the data. This process was further distilled until reaching a point where the global themes emerged from the data. During the second coding phase, we intensively examined the commonalities, differences and relationships, which enabled us to scrutinize the emerging global themes to achieve an understanding free of contradictions (Arnold and Fischer, 1994). These global themes were grounded empirically in the data and we provide evidence in the form of illustrative quotes depicted below. When additional focus groups and managerial interviews stopped generating new thematic ideas, and when any new generated data could fit into the identified global themes, we stopped the sampling, data collection and data analysis. Ultimately, the identified 10 negative impacts and 6 contingencies represent all the theory-laden data from the study. 
Finally, aiming for theoretical saturation, negative case analysis was used for these purposes as advised by Bowen (2008). Using the negative case analysis, we looked at the data again trying to find cases that contradict the emergent themes. Once no negative cases were identified, we considered the analysis complete and the boundaries of the negative impacts and contingencies set. During the whole coding process, as advised by Kidd and Parshall (2000), all efforts have been made to secure internal consistency: the main author served as primary moderator and coder while frequently communicating with the rest of the team who played the role of research "auditors" (Bowen, 2008). Content validity was also respected, as although the coding was done by the main author, the rest of the team independently verified the coding scheme and reached consensus regarding the identified global themes (Atwood and Hinds, 1986). This has been performed until the point where it became obvious that if others had to analyze the data independently using the same transcripts, similar conclusions would have been drawn (Bowen, 2008).

In sum, seven focus groups with a total of 45 FLEs and 22 in-depth semi-structured interviews with middle and top managers were conducted across seven service companies in the UK, representing various service industries including: utilities, banking, and support services sectors. Each focus group consisted of six to eight male and female employees and lasted between 70 and 90 minutes. Each managerial interview lasted between 45 and 60 minutes. Finally, all interviews were conducted face-to-face at the organizations’ premises and were audio-recorded and transcribed verbatim.

\section{Results and discussion}

The data analysis identified several negative impacts of PCF. It also revealed the unexpended finding that PCF could have no or minimal impact. Finally, the exploratory nature of our study also helped us discover that the identified negative impacts may be contingent on a variety of factors (contingencies of PCF) that play a crucial role in determining the direction and intensity of the negative impact of PCF.

\section{Negative impact of positive customer feedback}

Pressure from raised expectations:

Positive feedback can put pressure on FLEs as it raises the expectations for the future. This finding comes in accordance with Baumeister et al. (1990) who found that praise creates excessive pressure to continue performing well. The raised expectations pressurize the employee to keep working harder without setting a benchmark. Thus, it might reach a peak point where the employee performance might collapse as one employee 
explained: '... and if you keep doing that you get to the point where you ... have that monumental fall back to recalibrate and reset' (Male, FG 7, retail sector).

\section{Risk aversion:}

As a result of receiving PCF, employees might become risk averse as one employee mentioned: '...we don’t want to do the wrong thing... Just safeguarding yourself' (Male, FG 1, banking sector). This finding is in accordance with Gunderson et al. (2013) who found that praise creates excessive pressure to continue performing well and discourage risk taking. Another participant confirmed: 'If you say you're on this account for 12 months, you just need to hit that target, you hit that, move on and hope the next person doesn't find out what's happened' (Male, FG 7, retail sector). Therefore, as found by Kotlyar et al. (2014), perceived public scrutiny is another reason why praised employees become risk averse.

\section{Service bias:}

The participants mentioned that PCF might cause them to start favoring customers who give them positive feedback. One participant mentioned:

You've got to maintain the same level of professionalism, but it is easier to have your favorites, it is easier to just go above and beyond because they are being nice to you (Female, FG 6, utilities sector).

As explained by Plé and Cáceres (2010), FLEs are service systems interacting with two other systems the organization and the customers. Therefore, being in this position, they can use or misuse their own resources (e.g. skills and knowledge) and/or the resources of the organization and the customers. Employees might therefore choose to engage in "sabotage behaviors” (Harris and Ogbonna, 2002, p. 166) to increase their own well-being while disregarding the well-being of the organization. This comes in accordance with Patterson et al. (2006) who found that employees might compromise their equity to encourage or maintain a harmonious relationship with customers and initiate a cycle of reciprocity.

\section{Embarrassment:}

Positive feedback can be embarrassing for some employees to handle. One participant mentioned: ‘...and I wish I was not in that room, because I don’t know what to say, I don't know how to react, because I feel really embarrassed' (Female, FG 3, support services provider). Goffman (1956) interchangeably uses the terms 
“embracement”, "discomfiture," and "uneasiness" that “occurs whenever an individual is felt to have projected incompatible definitions of himself before those present” (p. 264).

\section{Humiliation:}

For some employees, receiving PCF may be perceived as patronizing, in the sense that it can imply that the person is not competent enough. One participant mentioned: 'I find as well there’s a fine line between giving praise and being patronizing sometimes... say you've done a good job but then (they) say, oh well done, like as if you didn’t have it in you’ (Male, FG 3, support services provider). This finding aligns with Meyer's (1992) finding that complimenting people on easy and routine tasks might suggest that the person is perceived to have a low-ability.

\section{Surface acting:}

FLEs feel pressured to "reciprocate” the positive feedback received. The reciprocation might involve additional actions (e.g. increased work load) but it could also include reciprocation of displayed emotions. An employee stated: 'You do a lot of favors and gestures... without actually meaning them... But they [the customers] don't see it' (Female, FG 3, support services provider). This pressure to reciprocate forces the employee to engage in surface acting by faking affective positive displays (Hochschild, 2003), which can lead to exhaustion and burnout (Grandey, 2003).

\section{Experiencing role conflict:}

Another negative impact occurs when employees experience uncertainty about their subsequent actions, after receiving positive feedback. This supports the observations of Martin et al. (1999), who found that customers’ spontaneous and “unscripted” behaviors lead to input uncertainty and task difficulty for employees. One participant mentioned colleagues’ difficulties: “...they [employees] had a script and if the customer went off script [by giving a compliment], which a lot of them do, they didn't know what to do" (Female, FG 6, utilities sector). By giving positive feedback, the customer might be contributing to the creation of role conflict for the employee since the employee's perception of the customer's expectations after the compliment may not be aligned with employees’ service role scripts (Hsieh et al., 2004).

Increased workload:

Respondents mentioned that positive feedback in the form of positive word of mouth or customer loyalty to a particular service provider can increase the workload of specific FLEs. A customer might recommend a particular employee or team; 'why don't you go to my branch, they're always friendly, they'll always look after 
you' (Male, FG 1, banking sector) or choose the person who served them; 'a lot of the customers that would wait specifically for me, for example, when there’s a queue’ (Male, FG 1, banking sector).

Moreover, the pressure to "reciprocate” PCF might result in employees performing tasks that fall outside their normal duties. An employee mentioned that when a customer gives him a compliment, it feels like the customer is saying ‘do us a favor’ (Male, FG 6, utilities sector). The norm of reciprocity (Gouldner, 1960) as part of social exchange (Blau, 1964), has long been studied by organizational researchers to explain why individuals engage in behaviors that typically are neither formally rewarded nor contractually demanded (Rousseau, 1989). In particular, it is found that positive, beneficial actions directed at employees by the organization and/or its representatives create obligations for employees to reciprocate in positive ways aiming to contribute to the establishment of high-quality exchange relationships (Konovsky and Pugh, 1994).

Therefore, we found that PCF creates obligations for employees to reciprocate, mainly by performing additional tasks that increase their workload, to maintain the high-quality exchange relationship.

\section{Complacent behavior:}

In contrast to increased workload, PCF can lead to complacent employee behavior, leading to a declining service performance:

Yes, it's good for someone to say thank you but normally I don't like too much thank you ... if you get a thank you too much, sometimes you relax... nothing is challenging (Male, FG 3, support services provider).

Complacent behavior was also brought up by managers as they confirmed that the performance of employees who continuously receive PCF might suffer as they use positive feedback as an excuse to justify and rationalise their mistakes.

Internal confrontation:

Another negative impact of PCF can occur when it is associated with internal confrontations. According to the managers, PCF can be the cause of unhealthy friction and competition between employees: 'Because I always believe if you put yourself up there, there's always someone who wants to knock you down' (Female, Interview 9, support services provider).. Moreover, PCF to one person, might contain or lead to a complaint about another person within the same organization.

The competition can go beyond the employee level to reach the managerial level, where it can take the form of self-interest, as opposed to company-interest, since the success of the employee is a reflection of his 
manager's success, as one manager noted: 'Yes, he’s (employee) one of mine and good for my bonus and career as well’ (Male, Interview 7, support services provider). . This internal confrontation might lead to workplace deviance. Robinson and Bennett (1995) define workplace deviance as voluntary behaviors or actions that violate company's norms and threaten its well-being or the well-being of its members. Walsh (2014) found that extra-organizational factors, customers in particular, influence employee well-being and tendency towards deviant behaviors. While, Wang et al. (2011) confirm that managers and the climate they shape represent a social contextual resource that can make employee’s deviant behavior less likely to occur. Although uncivil and unfriendly customers might cause employee deviance (Harris and Reynolds, 2004), we propose that PCF might cause employee deviance if not properly managed and communicated.

\section{No or minimal impact of positive customer feedback}

Contrasting the literature reviewed highlighting either positive or negative impact of positive feedback, our study reveals that PCF in a service encounter can also surprisingly have minimal or no impact on FLEs. One employee mentioned: 'actually there is that thought that I’ve just done what I should have done...I've done what I get paid to do' (Female, FG 2, banking sector).. This finding is in line with organizational behaviour research that advocates that negative feedback enhances performance and positive feedback gives "message that performance is on target" and thus "few changes would be expected" in performance (Podsakoff and Farh, 1989, p. 47).

Moreover, as opposed to Luthans and Kreitner's (1985) findings, our results show that positive feedback in the form of formalised internal awards (where customers nominate particular employees for an award for service excellency) might not be motivational, 'Personally I don't bother about XXX awards, I just do the job I do, and if I get a thank you, I get a thank you, and if I don't, I don't’ (Male, FG 6, utilities sector).

\section{Contingencies of positive customer feedback}

We have identified six contingencies (Table 1) interfering in the impact process: These contingencies play a crucial role in determining the direction and intensity of the negative impact of PCF; negating, intensifying or controlling the negative impacts.

Insert Table 1 about here 
The identified contingencies make the management of positive feedback a challenging task. For example, with regards to the subjective nature of PCF, keeping in mind the various employees’ personalities, perceptions and characteristics, managing the direct and indirect recipients of praise is a very challenging issue for managers, in particular when the issue of fairness and justice comes into play. Another example is the issue of authenticity as managers tend to question the authenticity of PCF received. The identified reasons for this questioning are: personal recognition, source reasons, and politeness. Managers highlighted that some employees might over rely on recognition as motivation, rather than reaching the set goals. Thus, some employees would go the extra mile just to be publicly recognised, rather than for the sake of improved performance. Other managers doubted the source of the feedback as it might be family and friends who are supporting their relative or friend by giving positive feedback about him/her. One manager confirmed that politeness and the desire to avoid confrontation is what encourages people to give positive inauthentic feedback. When PCF is not authentic it might play the role of verbal bribery: a verbal manipulation serving the interest of the person giving it. Thus, the identified contingencies do not only affect the direction and intensity of the impact of PCF on the employees but also put pressure on managers as they question the motives and the source of the positive feedback and as they deal with the current feedback management system and expectation standards.

\section{Model development}

Based on the findings, we propose the following theoretical model (Figure 1):

Insert Figure 1 about here

Figure 1 portrays the relationship between PCF (column 1) and the negative impact on FLE well-being (column 3) being contingent upon a variety of key factors (see table 2, column 3).

In total, the identified impacts negatively affect the eudaimonic and hedonic well-being dimensions of FLEs. PCF can have a negative impact on the eudaimonic dimensions such as harmony (for example, through embarrassment), respect (for example, through humiliation) and support (for example, through increased internal confrontation) and appears to increase the negative affect by increasing tension, fear, strain, stress (for example, through the created pressure from raising expectations). Thus, PCF can negatively affect the happiness 
level of FLEs (hedonic well-being). Therefore, the overall psychological well-being level of FLEs can suffer as a result of PCF. Finally, we found that most of the identified negative impacts as well as the contingencies of PCF are continuously interfering and interacting with each other, making it challenging to find or predict one particular impact or contingency at play in a particular context.

\section{Managerial implications}

Whilst most interviewed managers confirmed that their organizations had sophisticated procedures and policies regarding customer complaints management, none had developed guidelines for the management of PCF. Moreover, our data analysis showed various managerial challenges associated with PCF management. Accordingly, recognizing the significant triple impact of PCF (none/minimal, positive and negative) should constitute a first step to incorporating systematic management of PCF in service organizations. Hence, below we present some managerial implications that could help mitigate the identified negative impacts and make the management of PCF less challenging for FLEs, managers and organizations.

When managing positive feedback, managers should be aware of the importance of authenticity and subjectivity. Customers have been found to be able to detect inauthenticity (Grandey et al., 2005), similarly FLEs, in this study, gave a number of examples where they were equally able to detect inauthentic PCF.

Having identified “management of positive feedback” as one of the contingencies of PCF, managerial implications with regards to this contingency are presented:

First, taking the identified impacts and contingencies of PCF as a starting point, we propose that some of these impacts and contingencies could be applicable to managerial praise as well. For example, in many cases, a strong relationship between the manager and the FLE can help the employee perceive managerial praise as sincere and authentic. Moreover, it can help create an environment where positive feedback is freely shared and discussed. In contrast, a less-transparent or conflict driven relationship between the two, might cause the employee to perceive positive feedback as embarrassing, humiliating, manipulative, pressuring or controlling. We suggest that managers should deliver and encourage specific and detailed positive feedback. Managers should be aware of the importance of paying attention to how they praise for achievements that come easily, such as routine tasks, as this praise can have a demotivating effect, be considered offensive, and eventually lead to complacent behavior (Meyer, 1992). Therefore, it is recommended that managers differentiate between the degrees of praise needed for exceptional performance as opposed to regular praise for routine tasks. Moreover, the content of the positive feedback given should be focused on the mastering of performance skills not on comparing the employee to others. Thus, avoiding internal confrontation and unhealthy internal competition, leading to conflicts and job burnout. By focusing the positive feedback on performance skills that convey 
realistic, attainable standards, ethical problems such as bullying or sexual harassment could be more easily avoided.

Second, managers should encourage PCF sharing while keeping an eye on the possible negative impacts identified in this study. For example, this could be achieved by designing promotional and social media campaigns supporting sincere conversation and dialogue between customers and FLEs. Moreover, the identified impacts could be used by companies when designing solicited customer feedback programs, including feedback forms and questions. For example, by including specific questions designed to trigger authentic and sincere answers and by rephrasing and re-asking similar questions to make sure that the answers remain consistent. Furthermore, to mitigate the negative impacts such as role conflict and internal confrontations, forms and questions should be content specific and nondiscriminatory - for example, avoiding employee ranking.

Third, organizations should inform their employees about possible PCF impacts. Accordingly, employees could be trained on how to interpret and respond to PCF, when planning and executing their jobs. Role playing could be used in these training sessions, and service scripts could be designed to help employees respond to the various types of PCF. This strategy could contribute to decreasing the role conflict that employees might experience as a result of PCF. In addition, the identified impacts could be included as criteria in the recruitment process, where candidates are screened vis-a-vis their personalities and capacities to deal with and respond to the different types of customer feedback. In addition to the task-related knowledge that FLEs need, a certain level of emotional intelligence is necessary to deal with customer feedback. The candidate’s responses to different hypothesized examples of customer feedback should be a recognized criteria in the selection process.

Finally, managers could also attend sessions designed to stress the importance of FLE psychological well-being, its eudaimonic and hedonic dimensions, and the direct and indirect costs associated with its neglect. These sessions could be delivered by members of the growing community of occupational psychologists and organizational behavior researchers offering consultancy in the field of workplace happiness and well-being.

\section{Limitations and directions for future research}

This study has several limitations. First, this is a small-scale exploratory study: however, all efforts to reach theoretical saturation were made (Strauss and Corbin, 1998). Another limitation of this study is the risk of conformity of opinions in the focus groups (Garfinkel, 1967); however, all efforts have been made to diversify the focus group members and to encourage a dynamic exchange of opinions and ideas. Finally, we are aware about the possibility of the interviewer biasing the respondents when conducting the managerial personal interviews. However, the interviewer, who is trained and experienced at this method, attempted to minimize the 
learning process and this has been later verified by the members of the research team when reviewing the transcripts by checking the interviewer questions and participants responses to make sure that the interviewer was unbiased, consistent throughout all the interviews, and avoided asking leading questions.

In terms of future research, undoubtedly, the most important aspect is further testing of the identified impacts. We invite researchers to design scales that will help measure the various identified negative impacts of PCF and show which impacts are stable across different contexts, and which impacts are situation or context specific. This study was conducted across several service industries and similar patterns emerged, thus it is a good basis for scale development.

Moreover, we invite researchers to consider and identify further situation specific moderators. As an example, an interesting moderator might be the quality and nature of the relationship (manipulative/ sincere) between the FLE and the customer giving the positive feedback. Other important moderators that may be worth considering in these tests are personality traits, gender and age as previous research shows that different genders and ages respond to praise differently (Corpus and Lepper, 2007). In addition, we propose that further contingency factors, not identified in this study, might affect the intensity of the negative impact such as the facility design (Kok et al., 2015) and the presence of other employees/customers, we encourage future research to look further into these factors. Finally, it will be interesting to identify and compare under which conditions PCF can have a positive impact on FLE well-being.

Most of the research on praise has been conducted in western societies (Corpus and Lepper, 2002), including this study, therefore we cannot generalize these findings cross-culturally. In addition, service encounters are social exchanges (Patterson et al., 2006), thus, the norms, roles, and expectations of both employees and customers are influenced by each party’s cultural setting. Thus, positive feedback might have different impacts in collectivist as opposed to individualist societies. Acknowledging these cultural differences, we invite researchers to test the identified negative impacts cross-culturally.

As for future methods of data collection, we support Ranjan et al. (2015) call for conducting more dyadic research when studying service encounters and invite researchers to use a dyadic methodology that measures both customer and employee attitudes and perceptions towards giving and receiving PCF.

We do not decry the importance of all types of feedback, but organizations need to be careful about how they manage both positive and negative customer feedback. We believe that it is crucial to continue the work regarding the negative impact of PCF, especially through the TSR lens, as what might be believed to have a positive impact can be detrimental to the well-being of some service and consumer entities.

\section{REFERENCES}


Anderson, L., Ostrom, A.L., Corus, C., Fisk, R.P., Gallan, A.S., Giraldo, M., Mende, M., et al. (2013), “Transformative service research: An agenda for the future”, Journal of Business Research, Vol. 66 No. 8, pp. 1203-1210.

Arnold, S.J. and Fischer, E. (1994), “Hermeneutics and consumer research”, Journal of Consumer Research, Vol. 21 No. 1, pp. 55-70.

Ashforth, B.E. and Humphrey, R.H. (1993), "Emotional labor in service roles: the influence of identity", The Academy of Management Review, Vol. 18 No. 1, pp. 88-115.

Atwood, J.R. and Hinds, P. (1986), "Heuristic heresy: Application of reliability and validity criteria to products of grounded theory”, Western Journal of Nursing Research, Vol. 8 No. 2, pp. 135-154.

Avey, J.B., Luthans, F., Smith, R.M. and Palmer, N.F. (2010), "Impact of positive psychological capital on employee well-being over time.”, Journal of Occupational Health Psychology, Vol. 15 No. 1, pp. 17-28.

Babbar, S. and Koufteros, X. (2008), “The human element in airline service quality: contact personnel and the customer”, International Journal of Operations \& Production Management, Vol. 28 No. 9, pp. 804-830.

Bakker, A.B. and Demerouti, E. (2007), “The job demand-resources model: State of the art”, Journal of Managerial Psychology, Vol. 22 No. 3, pp. 309-328.

Bandura, A. (1997), Self-efficacy: The Exercise of Control, Freeman, New York, NY.

Bandura, A. and Cervone, D. (1986), "Differential engagement of self-reactive influences in cognitive motivation”, Organizational Behavior and Human Decision Processes, Vol. 38 No. 1, pp. 92-113.

Baron, S., Warnaby, G. and Hunter-Jones, P. (2014), "Service(s) marketing research: Developments and directions”, International Journal of Management Reviews, Vol. 16 No. 2, pp. 150-171.

Baumeister, R.F., Hutton, D.G. and Cairns, K.J. (1990), "Negative effects of praise on skilled performance”, Basic and Applied Social Psychology, Routledge, Vol. 11 No. 2, pp. 131-148.

Bettencourt, L.A., Gwinner, K.P. and Meuter, M.L. (2001), “A comparison of attitude, personality, and knowledge predictors of service-oriented organizational citizenship behaviors”, Journal of Applied Psychology, Vol. 86 No. 1, pp. 29-41.

Birch, L.L., Marlin, D.W. and Rotter, J. (1984), “Eating as the“ means’ activity in a contingency: Effects on young children’s food preference”, Child Development, Vol. 55 No. 2, pp. 431-439.

Bitner, M.J. (2014), "Editorial: A vision for the future of the journal of service research (JSR)”, Journal of Service Research, Vol. 17 No. 1, pp. 3-4.

Bitner, M.J., Booms, B.H. and Mohr, L.A. (1994), "Critical service encounters : The employee 's viewpoint”, Journal of Marketing, Vol. 58 No. 4, pp. 95-106.

Blau, P.M. (1964), Exchange and Power in Social Life, Wiley, New York, NY.

Blumenfeld, P.C., Pintrich, P.R., Meece, J. and Wessels, K. (1982), "The formation and role of self perceptions of ability in elementary classrooms”, The Elementary School Journal, Vol. 42, pp. 401-420.

Bowen, G.A. (2008), "Naturalistic inquiry and the saturation concept: a research note”, Qualitative Research, Vol. 8 No. 1, pp. 137-152.

Briggs, E., Jaramillo, F. and Noboa, F. (2015), “Explicating customer orientation’s influence on frontline employee satisfaction”, The Service Industries Journal, Vol. 35 No. 3, pp. 133-151.

Brynjolfsson, E. and McAfee, A. (2011), Race Against the Machine, Digital Frontier Press, Lexington, Mass.

Carnegie, D. (1964), How to Win Friends and Influence People, Simon \& Schuster, New York, NY.

Chan, K.W., Yim, C.K. (Bennett) and Lam, S.S.K. (2010), "Is customer participation in value creation a double-edged sword ? Evidence from professional financial services across cultures", Journal of Marketing, Vol. 74 No. May, pp. 48-64.

Corpus, J.H. and Lepper, M.R. (2002), “The effects of praise on children's intrinsic motivation: A review and synthesis.”, Psychological Bulletin, Vol. 128 No. 5, pp. 774-795.

Corpus, J.H. and Lepper, M.R. (2007), “The effects of person versus performance praise on children’s motivation: Gender and age as moderating factors”, Educational Psychology, Vol. 27 No. 4, pp. 487-508.

Corpus, J.H., Ogle, C.M. and Love-Geiger, K.E. (2006), "The effects of social-comparison versus mastery praise on children's intrinsic motivation”, Motivation and Emotion, Vol. 30 No. 4, pp. 333-343. 
Daunt, K.L. and Harris, L. (2014), "Linking employee and customer misbehaviour: The moderating role of past misdemeanours”, Journal of Marketing Management, Vol. 30 No. 3-4, pp. 221-244.

Deci, E.L. and Ryan, R.M. (1985), Intrinsic Motivation and Self-Determination in Human Behavior, Taylor \& Francis, New York, NY.

Delin, C.R. and Baumeister, R.F. (1994), “Praise: More than just social reinforcement”, Journal for the Theory of Social Behavior, Vol. 24 No. 3, pp. 219-241.

Diener, E., Suh, E.M., Lucas, R.E. and Smith, H.L. (1999), “Subjective well-Being: Three decades of progress”, Psychological Bulletin, Vol. 125 No. 2, pp. 276-302.

Van Dijk, D. and Kluger, A.N. (2011), “Task type as a moderator of positive/negative feedback effects on motivation and performance: A regulatory focus perspective”, Journal of Organizational Behavior, Vol. 32 No. 8, pp. 1084-1105.

Doi, Y. (2005), “An epidemiologic review on occupational sleep research among Japanese workers”, Industrial Health, Vol. 43 No. 1, pp. 3-10.

Edmondson, D.R. and Boyer, S.L. (2013), “The moderating effect of the boundary spanning role on perceived supervisory support: A meta-analytic review”, Journal of Business Research, Vol. 66 No. 11, pp. 21862192.

Eisenberger, R., Fasolo, P. and Davis-LaMastro, V. (1990), "Perceived organizational support and employee diligence, commitment, and innovation”, Journal of Applied Psychology, Vol. 75 No. 1, pp. 51-59.

Erickson, S.G. and Ecktich, D.W. (2001), “Consumer affairs responses to unsolicited customer compliments”, Jounral of Marketing Management, Vol. 17, pp. 321-340.

Farrell, M.A. and Oczkowski, E. (2012), “Organisational identification and leader member exchange influences on customer orientation and organisational citizenship behaviours”, Journal of Strategic Marketing, Vol. 20 No. 4, pp. 365-377.

Fisk, R. (2009), “A Customer liberation manifesto”, Service Science, Vol. 1 No. 3, pp. 135-141.

Garfinkel, H. (1967), Studies in Ethnomethodology, Prentice-Hall, Englewood Cliffs, NJ.

Ginott, H.G. (1965), Between Parent and Child, MacMillan, New York, NY.

Goffman, E. (1956), “Embarrassment and social organization”, American Journal of Sociology, Vol. 62 No. 3 , pp. 264-271.

Gouldner, A.W. (1960), “The norm of reciprocity: A preliminary statement”, American Sociological Review, Vol. 25 No. 2, pp. 161-178.

Grandey, A.A. (2003), "When 'the show must go on': Surface acting and deep acting as determinants of emotional exhaustion and peer-rated service delivery”, Academy of Management Journal, Vol. 46 No. 1, pp. 86-96.

Grandey, A.A., Fisk, G.M., Mattila, A.S., Jansen, K.J. and Sideman, L.A. (2005), “Is 'service with a smile' enough? Authenticity of positive displays during service encounters”, Organizational Behavior and Human Decision Processes, Vol. 96 No. 1, pp. 38-55.

Gunderson, E.A., Gripshover, S.J., Romero, C., Dweck, C.S., Goldin-Meadow, S. and Levine, S.C. (2013), "Parent praise to 1- to 3-year-olds predicts children's motivational frameworks 5 years later.", Child Development, Vol. 84 No. 5, pp. 1526-1541.

Harris, L. and Ogbonna, E. (2002), "Exploring service sabotage: The antecedents, types and consequences of frontline, deviant, antiservice behaviors”, Journal of Service Research, Vol. 4 No. 3, pp. 163-183.

Harris, L. and Reynolds, K.L. (2003), “The Consequences of dysfunctional customer behavior”, Journal of Service Research, Vol. 6 No. 2, pp. 144-161.

Harris, L. and Reynolds, K.L. (2004), "Jaycustomer behavior: an exploration of types and motives in the hospitality industry”, Journal of Services Marketing, Vol. 18 No. 5, pp. 339-357.

Harter, J.K., Schmidt, F.L. and Hayes, T.L. (2002), “Business-unit-level relationship between employee satisfaction, employee engagement, and business outcomes: a meta-analysis”, Journal of Applied Psychology, Vol. 87 No. 2, pp. 268-279.

Hartline, M.D. and Ferrell, O.C. (1996), "The management of customer-contact service employees : An emperical investigation”, Journal of Marketing, Vol. 60 No. 4, pp. 52-70. 
Hartline, M.D., Maxham III, J.G. and McKee, D.O. (2000), "Corridors of influence in the dissemination of customer-oriented strategy to customer contact service employees”, Journal of Marketing, Vol. 64 No. 2, pp. 35-50.

Hattie, J. and Timperley, H. (2007), “The power of feedback”, Review of Educational Research, Vol. 77 No. 1, pp. 81-112.

Van der Heijden, G.A.H., Schepers, J.J.L., Nijssen, E.J. and Ordanini, A. (2013), “Don’t just fix it, make it better! Using frontline service employees to improve recovery performance”, Journal of the Academy of Marketing Science, Vol. 41 No. 5, pp. 515-530.

Hochschild, A.R. (2003), The Managed Heart: Commercialization of Human feeling with a New Afterword, Univ of California Press, Los Angeles, CA.

Hsieh, A.-T., Yen, C.-H. and Chin, K.-C. (2004), "Participative customers as partial employees and service provider workload”, International Journal of Service Industry Management, Vol. 15 No. 2, pp. 187-199.

Kanouse, D.E., Gumpert, P. and Canavan-Gumpert, D. (1981), “The semantics of praise”, New Directions in Attribution Research, Vol. 3, pp. 97-115.

Kidd, P.S. and Parshall, M.B. (2000), "Getting the focus and the group: enhancing analytical rigor in focus group research”, Qualitative Health Research, Vol. 10 No. 3, pp. 293-308.

Koestner, R., Franz, C. and Weinberger, J. (1990), "The family origins of empathic concern: A 26-year longitudinal study”, Journal of Personality and Social Psychology, Vol. 58 No. 4, pp. 709-717.

Koestner, R., Zuckerman, M. and Koestner, J. (1989), “Attributional focus of praise and children’s intrinsic motivation the moderating role of gender”, Personality and Social Psychology Bulletin, Vol. 15 No. 1, pp. 61-72.

Kohn, A. (1993), Punished by Rewards: The Trouble with Gold Stars, Incentive Plans, A's, Praise, and Other Bribes, Houghton Mifflin Harcourt, Boston, MA.

Kok, H., Mobach, M. and Omta, O. (2015), “Facility design consequences of different employees’ quality perceptions”, The Service Industries Journal, Vol. 35 No. 3, pp. 152-178.

Konovsky, M.A. and Pugh, D.S. (1994), “Citizenship behavior and social exchange”, Academy of Mangement Journal, Vol. 37 No. 3, pp. 656-669.

Kotlyar, I., Karakowsky, L., Ducharme, M.J. and Boekhorst, J.A. (2014), “Do 'rising stars' avoid risk?: statusbased labels and decision making”, Leadership \& Organization Development Journal, Vol. 35 No. 2, pp. 121-136.

Kraft, F. and Martin, C. (2001), “Customer compliments as more than complementary feedback”, Journal of Consumer Satisfaction, Dissatisfaction and Complaining Behavior, Vol. 14, pp. 1-13.

Locke, K. (2001), Grounded Theory in Management Research, Sage, Thousand Oaks, CA.

London, M. and Smither, J.W. (2002), "Feedback orientation, feedback culture, and the longitudinal performance management process”, Human Resource Management Review, Vol. 12 No. 1, pp. 81-100.

Lovelock, C. and Wirtz, J. (2010), Services Marketing: People, Technology, Strategy, Prentice-Hall Series in Marketing, Prentice Hall, 7thed.

Lusch, R.F., Vargo, S.L. and O’Brien, M. (2007), “Competing through service: insights from service-dominant logic”, Journal of Retailing, Vol. 83 No. 1, pp. 5-18.

Luthans, F. (2002), “The need for and meaning of positive organizational behavior”, Journal of Organizational Behavior, Vol. 23 No. 6, pp. 695-706.

Luthans, F. and Kreitner, R. (1985), Organizational Behavior Modification and Beyond, Scott, Foresman, Glenview, IL.

Luthans, F. and Youssef, C.M. (2004), “Human, social, and now positive psychological capital management”, Organizational Dynamics, Vol. 33 No. 2, pp. 143-160.

Madsen, C.H., Becker, W.C. and Thomas, D.R. (1977), "Rules, praise, and ignoring: Elements of elementary classroom control”, in O’Leary, K.D. and O’Leary, S.G. (Eds.),Classroom Management: The Successful Use of Behavior Modification, Pergamon Press, New York, NY, pp. 63-84.

Martin, C.R., Horne, D.A. and Schultz, A.M. (1999), "The business-to-business customer in the service innovation process”, European Journal of Innovation Management, Vol. 2 No. 2, pp. 55-62. 
Maynard, A.E. (2002), “Cultural teaching: The development of teaching skills in maya sibling interactions”, Child Development, Vol. 73 No. 3, pp. 969-982.

McCracken, G. (1988), The Long Interview, Sage, Newbury Park, CA, Vol. 13.

Meyer, W.-U. (1992), "Paradoxical effects of praise and criticism on perceived ability”, European Review of Social Psychology, Vol. 3 No. 1, pp. 259-283.

Money, K., Hillenbrand, C. and Camara, N.D. (2009), "Putting positive psychology to work in organisations”, Journal of General Management, Vol. 34 No. 3, pp. 21-36.

Morgan, D.L. and Spanish, M. (1984), “Focus groups: A new tool for qualitative research”, Qualitative Sociology, Vol. 7 No. 3, pp. 253-270.

Morse, J.M. (1995), “The significance of saturation”, Qualitative Health Research, No. 2, pp. 147-149.

Morse, J.M., Barrett, M., Mayan, M., Olson, K. and Spiers, J. (2002), "Verification strategies for establishing reliability and validity in qualitative research”, International Journal of Qualitative Methods, Vol. 1 No. 2, pp. 13-22.

Mueller, C.M. and Dweck, C.S. (1998), "Praise for intelligence can undermine children's motivation and performance.”, Journal of Personality and Social Psychology, Vol. 75 No. 1, pp. 33-52.

Myers, D.G. and Diener, E. (1995), “Who is happy?”, Psychological Science, Vol. 6 No. 1, pp. 10-17.

Nasr, L., Burton, J., Gruber, T. and Kitshoff, J. (2014), "Exploring the impact of customer feedback on the wellbeing of service entities: A TSR perspective”, Journal of Service Management, Vol. 25 No. 4, pp. 531555.

O’Leary, K. and O’Leary, S. (1972), “Behavior modification with children”, in O’Leary, K. and O’Leary, S. (Eds.),Classroom Management: The Successful Use of Behavior Modification with Children, Pergamon, New York, NY, pp. 1-48.

Ostrom, A.L., Bitner, M.J., Brown, S.W., Burkhard, K.A., Goul, M., Smith-Daniels, V., Demirkan, H., et al. (2010), "Moving forward and making a difference: Research priorities for the science of service”, Journal of Service Research, Vol. 13 No. 1, pp. 4-36.

Ostrom, A.L., Parasuraman, A., Bowen, D.E., Patricio, L. and Voss, C.A. (2015), "Service Research Priorities in a Rapidly Changing Context”, Journal of Service Research, Vol. 18 No. 2, pp. 127-159.

Patterson, P.G., Cowley, E. and Prasongsukarn, K. (2006), "Service failure recovery: the moderating impact of individual-level cultural value orientation on perceptions of justice”, International Journal of Research in Marketing, Vol. 23 No. 3, pp. 263-277.

Patton, M. (1990), Qualitative Evaluation and Research Methods, Sage, Beverly Hills, CA.

Payne, C.R., Parry, B.L., Huff, S.C., Otto, S.D. and Hunt, K.H. (2002), "Consumer complimenting behavior : Exploration and elaboration”, Journal of Consumer Satisfaction, Dissatisfaction and Complaining Behavior, Vol. 15, pp. 128-147.

Plé, L. and Cáceres, R.C. (2010), "Not always co-creation: introducing interactional co-destruction of value in service-dominant logic”, Journal of Services Marketing, Vol. 24 No. 6, pp. 430-437.

Podsakoff, P.M. and Farh, J.-L. (1989), "Effects of feedback sign and credibility on goal setting and task performance”, Organizational Behavior and Human Decision Processes, Vol. 44 No. 1, pp. 45-67.

Ranjan, K.R., Sugathan, P. and Rossmann, A. (2015), “A narrative review and meta-analysis of service interaction quality: New research directions and implications”, Journal of Services Marketing, Vol. 29 No. 1.

Robertson, I. and Cooper, C. (2011), Well-Being: Productivity and Happiness at Work, Palgrave MacMillan.

Robinson, S.L. and Bennett, R.J. (1995), “A typology of deviant workplace behaviors: A multidimensional scaling study”, Academy of Management Journal, Vol. 38 No. 2, pp. 555-572.

Rosenbaum, M.S., Corus, C., Ostrom, A.L., Anderson, L., Fisk, R.P., Gallan, A.S., Giraldo, M., et al. (2011), "Conceptualisation and aspirations of transformative service research", Journal of Research for Consumers, No. 19, pp. 1-6.

Rousseau, D.M. (1989), “Psychological and implied contracts in organizations”, Employee Responsibilities and Rights Journal, Vol. 2 No. 2, pp. 121-139. 
Rupp, D., Holub, S. and Grandey, A. (2007), “A cognitive-emotional theory of customer injustice and emotional labor: Implications for customer service, fairness theory, and the multifoci perspective”, in DeCremer, D. (Ed.),Advances in the Psychology of Justice and Effect, Information Age, Charlotte, NC, pp. 199-226.

Ryan, A.M. and Ployhart, R.E. (2003), “Customer service behavior”, in Borman, W.C., Ilgen, D.R. and Klimoski, R.J. (Eds.),Handbook of Psychology: Industrial and Organizational Psychology, Wiley, London, pp. 377-397.

Ryff, C.D. (1989), "Happiness is everything, or is it? Explorations on the meaning of psychological wellbeing.”, Journal of Personality and Social Psychology, Vol. 57 No. 6, pp. 1069-1081.

Stewart, D., Shamdasani, P. and Rook, D. (2007), Focus Groups Theory and Practice, Sage, London, UK.

Strauss, A. and Corbin, J. (1998), Basics of Qualitative Research: Techniques and Procedures for Developing Grounded Theory, Sage, Thousand Oaks, CA.

Surachartkumtonkun, J., McColl-Kennedy, J.R. and Patterson, P.G. (2015), “Unpacking customer rage elicitation : A dynamic model”, Journal of Service Research, Vol. 18 No. 2, pp. 177-192.

Tangney, J.P. and Dearing, R.L. (2002), Shame and Guilt, Guilford Press, New York, NY.

Teng, C.-C. and Barrows, C.W. (2009), "Service orientation: antecedents, outcomes, and implications for hospitality research and practice”, The Service Industries Journal, Vol. 29 No. 10, pp. 1413-1435.

Turner, B.A. (1981), "Some practical aspects of qualitative data analysis: One way of organizing the cognitive processes associated with the generation of grounded theory”, Quality and Quantity, Vol. 15, pp. $225-247$.

Villarroel Ordenes, F., Burton, J., Theodoulidis, B., Gruber, T. and Zaki, M. (2014), “Analyzing customer experience feedback using text mining: A linguistics-based approach”, Journal of Service Research, Vol. 17 No. 3, pp. 278-295.

Waldersee, R. and Luthans, F. (1994), “The impact of positive and corrective feedback on customer service performance”, Journal of Organizational Behavior, Vol. 15 No. 1, pp. 83-95.

Walsh, G. (2014), "Extra- and intra-organizational drivers of workplace deviance”, The Service Industries Journal, Vol. 34 No. 14, pp. 1134-1153.

Wang, M., Liao, H., Zhan, Y. and Shi, J. (2011), “Daily customer mistreatment and employee sabotage against customers: Examining emotion and resource perspectives”, Academy of Management Journal, Vol. 54 No. 2, pp. 312-334.

Weehuizen, R.M. (2008), Mental Capital: The Economic Significance of Mental Health, Universitaire Pers Maastricht.

Weiner, B. (1992), Human Motivation: Metaphors, Theories, and Research, Sage, Newbury Park, CA.

Wirtz, J., Tambyah, S.K. and Mattila, A.S. (2010), “Organizational learning from customer feedback received by service employees: A social capital perspective”, Journal of Service Management, Vol. 21 No. 3, pp. 363-387.

Wood, A.M., Froh, J.J. and Geraghty, A.W.A. (2010), "Gratitude and well-being : A review and theoretical integration”, Clinical Psychology Review, Vol. 30 No. 7, pp. 890-905.

Yoon, M.H. and Suh, J. (2003), "Organizational citizenship behaviors and service quality as external effectiveness of contact employees”, Journal of Business Research, Vol. 56 No. 8, pp. 597-611. 